\title{
Proton magnetic resonance spectroscopy changes in the brainstem in patients after mild traumatic brain injury with loss of consciousness
}

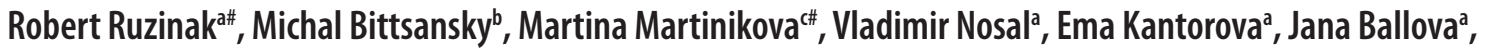 \\ Monika Turcanova Koprusakova a , Petra Hnilicovab ${ }^{b}$, Marian Grendarb, Robert Dusenkad , Branislav Kolarovszkie, \\ Kamil Zelenak', Egon Kurca ${ }^{a}$, Stefan Sivak ${ }^{a \#}$
}

\begin{abstract}
Introduction. Loss of consciousness (LOC) is used as a diagnostic feature of mild traumatic brain injury (MTBI). However, only $10 \%$ of concussions result in LOC. There are only a limited number of in-vivo studies dealing with unconsciousness and structural and functional integrity of the brainstem in patients with MTBI. The aim of our pilot study was to assess the sensitivity of proton magnetic resonance spectroscopy ( $\left.{ }^{1} \mathrm{H}-\mathrm{MRS}\right)$ to detect metabolic changes in the brainstem in patients after MTBI with unconscioussness.

Methods. Twenty-four patients ( 12 with LOC, and 12 without LOC) within 3 days of MTBI and 19 healthy controls were examined. All subjects underwent single-voxel ${ }^{1} \mathrm{H}$-MRS examination of the upper brainstem. Spectra were evaluated using LCModel software. Ratios of total $\mathrm{N}$-acetylaspartate (tNAA), total choline-containing compounds (tCho) and glutamate plus glutamine ( $\mathrm{Gl}$ x) to total creatine (tCre) were used for calculations.

Results. We found a significant decrease in $\mathrm{tNAA} / \mathrm{tCre}$ and $\mathrm{tCho/tCre} \mathrm{ratios} \mathrm{in} \mathrm{the} \mathrm{patient} \mathrm{group} \mathrm{with} \mathrm{LOC} \mathrm{when} \mathrm{com-}$ pared with the control group of healthy volunteers ( $P=0.002$ and $P=0.041$, respectively), and a significant decrease in the $\mathrm{NNAA} / \mathrm{tCre}$ ratio in the LOC group when compared with patients without LOC $(P=0.04)$. Other metabolite ratios in the brainstem did not show any significant group differences.
\end{abstract}

Conclusion. Our findings indicate that decrease of tNAA/tCre ratio in the upper brainstem using single-voxel ${ }^{1} \mathrm{H}-\mathrm{MRS}$ may provide a potential biomarker for MTBI associated with LOC.

Key words: mild traumatic brain injury, concussion, loss of consciousness, magnetic resonance spectroscopy

Received: November 18, 2020; Revised: April 20, 2021; Accepted: April 26, 2021; Available online: May 11, 2021

https://doi.org/10.5507/bp.2021.029

(c) 2022 The Authors; https://creativecommons.org/licenses/by/4.0/

${ }^{a}$ Clinic of Neurology, Jessenius Faculty of Medicine in Martin, Comenius University in Bratislava, Slovak Republic

${ }^{b}$ Biomedical Center Martin, Jessenius Faculty of Medicine in Martin, Comenius University in Bratilava, Slovak Republic

'Department of Neurology, F.D. Roosevelt Hospital, Banská Bystrica, Slovak Republic

${ }^{d}$ Clinic of Urology, Jessenius Faculty of Medicine in Martin, Comenius University in Bratislava, Slovak Republic

${ }^{e}$ Clinic of Neurosurgery, Jessenius Faculty of Medicine in Martin, Comenius University in Bratislava, Slovak Republic

${ }^{f}$ Clinic of Radiology, Jessenius Faculty of Medicine in Martin, Comenius University in Bratislava, Slovak Republic

"These authors contributed equally to the work

Corresponding author:Stefan Sivak,e-mail: sivakste@gmail.com

\section{INTRODUCTION}

Mild traumatic brain injury (MTBI) is a common neurotraumatological diagnosis. Loss of consciousness (LOC) lasting $30 \mathrm{~min}$ or less is a sign of MTBI, reported by $10 \%$ of patients ${ }^{1,2}$. LOC represents a form of brain dysfunction and is a sign of injury to the diffuse subcortical network of arousal pathways, called Ascending Arousal Network (AAn). AAn originates in the brainstem and via thalamic and extra-thalamic pathways activates awareness cortical networks ${ }^{3,4}$. AAn was first described by Moruzzi and Magoun in 1949 as Ascending Reticular Activating System (ARAS) $\left(\right.$ ref. $\left.^{5}\right)$. It is now known that AAn contains neurotransmitter specific nuclei and pathways (e.g. cholinergic, noradrenergic) that are not limited to the classical reticular core of ARAS (ref., ${ }^{3,6}$ ).

The brainstem is a vulnerable site in severe brain trauma associated with LOC caused by diffuse axonal injury ${ }^{7,8}$. Several experimental studies in animal models of MTBI with LOC have also demonstrated various structural and functional alterations in the brainstem ${ }^{9-12}$. Conventional structural magnetic resonance imaging (MRI) has been shown not to be sensitive enough to reveal acute traumatic changes in the brainstem even in patients with prolonged coma after severe traumatic brain injury ${ }^{13-15}$. Newer methods, such as magnetic resonance spectroscopy, diffusion tensor imaging or functional MRI, are more sensitive to postraumatic changes in normal appearing brain tissues than conventional MRI (ref. ${ }^{3,4,16-19}$ ).

Proton magnetic resonance spectroscopy ( $\left.{ }^{1} \mathrm{H}-\mathrm{MRS}\right)$ is a non-invasive technique which allows the detection and quantification of several brain metabolites including, but not limited to, $\mathrm{N}$-acetylaspartate plus $\mathrm{N}$-acetylaspartylglutamate signal (tNAA) - a marker of neuroaxonal integrity, choline-containing compound signal (tCho) - a marker of cellular membrane integrity, total creatine signal (tCre) - a marker of cellular energy status, and glutamate plus glutamine (Glx) - a marker of glia- 
neuron metabolism and excitotoxicity. ${ }^{1} \mathrm{H}-\mathrm{MRS}$ has been used in various studies in patients after MTBI and has proved more sensitive to the injuries missed by convectional structural MRI $\left(\right.$ ref. $\left.^{20}\right)$. In our previous study, using single-voxel ${ }^{1} \mathrm{H}-\mathrm{MRS}$, we unintentionally found a significant decrease in $\mathrm{N}$-acetylaspartate in the upper brainstem in a small subgroup of 7 patients with LOC after MTBI $\left(\right.$ ref. $\left.{ }^{21}\right)$. Due to these interesting findings, we decided to extend the study with larger groups of patients and healthy volunteers, as similar ${ }^{1} \mathrm{H}-\mathrm{MRS}$ studies focusing on MTBI and LOC are not present in specialist literature. The aim of this study was to assess whether ${ }^{1} \mathrm{H}-\mathrm{MRS}$ can detect metabolic changes in the brainstem and therefore be used as an objective biomarker for presence and duration of unconsciousness in patients after MTBI.

\section{MATERIAL AND METHODS}

\section{Participants}

Patients with MTBI (Patient group) and healthy volunteers (Control group) participated in the study. All subjects underwent a standard neurological examination and brain MRI with ${ }^{1} \mathrm{H}-\mathrm{MRS}$. MTBI was defined as any blow to the head resulting in a short-term impairment of neurological functions (unconsciousness lasting $30 \mathrm{~min}$ or less, confusion, disorientation, or post-traumatic amnesia lasting $24 \mathrm{~h}$ or less) which could be accompanied by other symptoms and signs (e.g. headache, nausea, vomiting, drowsiness, dizziness, emotional changes, cognitive deficits) (ref. ${ }^{1}$ ). Exclusion criteria for all subjects were: no witnesses of the patient trauma, age of under 18, previous traumatic brain injury, traumatic lesions detected by conventional MRI of the brain, history of chronic alcohol or drug abuse, a pre-existing neurological disorder (e.g. cerebrovascular disease, epilepsy, multiple sclerosis), any psychiatric disorder, arterial hypertension, and diabetes mellitus. Patients were divided into two groups based on the presence or absence of LOC (LOC and NoLOC groups), which was confirmed using collateral history or outside records, as patients are unaware of LOC due to post-traumatic amnesia. LOC was defined as unresponsiveness to external, verbal and somatosensory stimulations reported by one or more witnesses. Duration of LOC and post-traumatic amnesia (PTA) was established by collateral history or outside records.

\section{MRI and ${ }^{1} \mathrm{H}-\mathrm{MRS}$}

Patients and volunteers underwent magnetic resonance imaging and a spectroscopy session in our hospital MRI unit, using a 1.5 T Siemens Symphony scanner. The imaging part comprised of routine MRI protocols (T1-w, T2-w, FLAIR, T2*-w, and diffusion-weighted sequences) in order to exclude patients with visible traumatic lesions in the brain. The following conventional examination protocol was applied: sagittal T1-weighted spin-echo (SE): repetition time (RT) $444 \mathrm{~ms}$, echo time (ET) $8.6 \mathrm{~ms}$, section thickness (ST) $5 \mathrm{~mm}$, interslice gap (IG) $1 \mathrm{~mm}$; transversal T2-weighted turbo SE: RT 4330 ms, ET 92 ms, flip angle (FA) $150^{\circ}$, ST $5 \mathrm{~mm}$, IG $1 \mathrm{~mm}$; transversal FLAIR: RT $8510 \mathrm{~ms}$, ET $129 \mathrm{~ms}$, inversion time (IT) 2500 ms, ST $5 \mathrm{~mm}$, IG $1 \mathrm{~mm}$; coronal T2*-weighted GRE: RT $800 \mathrm{~ms}$, ET $26 \mathrm{~ms}$, FA 20․, ST $5 \mathrm{~mm}$, IG $1 \mathrm{~mm}$; transversal DWI: RT $3400 \mathrm{~ms}$, ET $97 \mathrm{~ms}$, ST 5 mm, IG $1.5 \mathrm{~mm}$; gradients were used at a low b value $(0 \mathrm{~s} / \mathrm{mm} 2)$ and a high $\mathrm{b}$ value $\left(1221 \mathrm{~s} / \mathrm{mm}^{2}\right.$ ), and ADC (Apparent Diffusion Coefficient) maps were calculated. A lesion was defined as traumatic in the presence of the following MRI pathological change: haemorrhages (T2*-GRE) or changes in water diffusion due to cytotoxic and/or vasogenic oedema (such DWI changes reflect cortical contusions and diffuse axonal injury, which are also hyperintense on FLAIR). Patients with traumatic lesions were not included in the study. Patients and controls with small nonspecific hyperintense lesions recognizable only on T2/FLAIR images were not excluded from the study. All ${ }^{1} \mathrm{H}-\mathrm{MRS}$ voxels were placed in normal-appearing brain tissue.

The spectroscopic voxel was measured using singlevoxel ${ }^{1} \mathrm{H}-\mathrm{MRS}$ in the upper brainstem (see Fig. 1). Spectra were shimmed individually using a combination of field mapping and manual shim adjustments, and were acquired using a PRESS sequence with these parameters: TE/TR $=135 / 4000$ ms, 100 averages, CHESS water suppression, ${ }^{1} \mathrm{H}$-MRS voxel volume of approx. $9 \mathrm{~mL}$. For each voxel, a separate water-unsuppressed MR spectrum was measured: TE/TR $=30 / 10000 \mathrm{~ms}, 2$ averages. The magnetic resonance session took approximately $50 \mathrm{~min}$. Data was processed automatically using LCModel software ${ }^{22}$. In order to avoid partial volume effects of cerebrospinal fluid, to make the protocol as simple as possible, and to avoid multiple comparisions, only the following metabolite ratios were used for statistical evaluation: $\mathrm{tNAA} / \mathrm{tCre}$, tCho/tCre, and Glx/tCre.

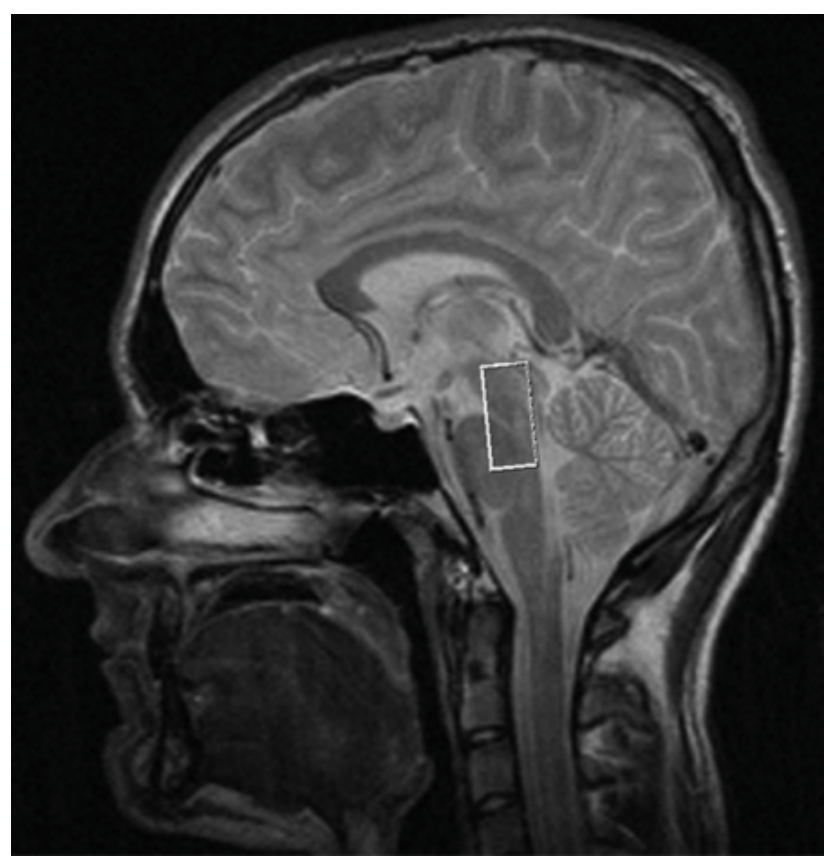

Fig. 1. MR spectroscopy voxel localization in the upper brainstem. 
Table 1. Demographic and clinical data.

\begin{tabular}{lcccc}
\hline & Control group & LOC group & NoLOC group & $P$ \\
\hline Patient $(\mathrm{n})$ & 19 & 12 & 12 & \\
Age $($ years, mean $\pm \mathrm{SD})$ & $31.37 \pm 11.38$ & $31.92 \pm 13.35$ & $33.0 \pm 10.83$ & 0.92 (Kruskal-Wallis test) \\
Gender (F/M) & $2 / 17$ & $1 / 11$ & $2 / 10$ & 0.855 (Fisher's exact test) \\
LOC duration (min, mean \pm SD) & 0 & $5.5 \pm 6.95$ & 0 & \\
PTA (Yes/No) & $0 / 19$ & $12 / 0$ & $12 / 0$ & \\
PTA duration (min, mean \pm SD) & 0 & $148.8 \pm 137.6$ & $170 \pm 268.4$ & 0.62 (LOC group vs. NoLOC \\
& & & & group; Mann Whitney U test) \\
\hline
\end{tabular}

LOC, loss of consciousness; NoLOC, no loss of consciousness; PTA, post-traumatic amnesia; SD, standard deviation; F, number of females; M, number of males

Table 2. Patients with MTBI with LOC.

\begin{tabular}{ccccccccc}
\hline $\begin{array}{l}\text { Patients with } \\
\text { LOC }\end{array}$ & Gender & $\begin{array}{c}\text { Age } \\
(\text { years })\end{array}$ & $\begin{array}{c}\text { LOC } \\
(\mathrm{min})\end{array}$ & $\begin{array}{c}\text { PTA } \\
(\mathrm{min})\end{array}$ & $\begin{array}{c}\text { MRI time-lapse } \\
(\mathrm{h})\end{array}$ & tNAA/tCre & tCho/tCre & Glx/tCre \\
\hline 1 & M & 23 & 2 & 11 & 62 & 2.103 & 0.42 & 1.5367 \\
2 & $\mathrm{M}$ & 26 & 1 & 450 & 38 & 2.103 & 0.4 & 1.9482 \\
3 & $\mathrm{M}$ & 26 & 10 & 120 & 70 & 1.942 & 0.4 & 1.5430 \\
4 & $\mathrm{M}$ & 54 & 1 & 240 & 34 & 2.102 & 0.48 & 0.1947 \\
5 & $\mathrm{~F}$ & 39 & 1 & 240 & 37 & 2.098 & 0.45 & 1.8787 \\
6 & $\mathrm{M}$ & 21 & 25 & 180 & 48 & 2.06 & 0.49 & 1.1790 \\
7 & $\mathrm{M}$ & 24 & 2 & 120 & 35 & 2.107 & 0.43 & 1.4012 \\
8 & $\mathrm{M}$ & 50 & 5 & 300 & 72 & 2.284 & 0.41 & 2.0931 \\
9 & $\mathrm{M}$ & 52 & 2 & 20 & 38 & 1.913 & 0.44 & 1.3230 \\
10 & $\mathrm{M}$ & 18 & 5 & 60 & 61 & 2.168 & 0.4 & 0.3856 \\
11 & $\mathrm{~F}$ & 19 & 10 & 15 & 64 & 2.825 & 0.52 & 1.0883 \\
12 & $\mathrm{M}$ & 31 & 2 & 30 & 55 & 2.026 & 0.44 & 1.2398 \\
\hline
\end{tabular}

MTBI, mild traumatic brain injury; LOC, loss of consciousness; PTA, post-traumatic amnesia; MRI time-lapse, time between trauma and MRI examination

Table 3. Patients with MTBI without LOC.

\begin{tabular}{ccccccccc}
\hline $\begin{array}{l}\text { Patients } \\
\text { with LOC }\end{array}$ & Gender & $\begin{array}{c}\text { Age } \\
(\text { years })\end{array}$ & $\begin{array}{c}\text { LOC } \\
(\mathrm{min})\end{array}$ & $\begin{array}{c}\text { PTA } \\
(\mathrm{min})\end{array}$ & $\begin{array}{c}\text { MRI time-lapse } \\
(\mathrm{h})\end{array}$ & tNAA/tCre & tCho/tCre & Glx/tCre \\
\hline 1 & $\mathrm{M}$ & 40 & 0 & 900 & 24 & 2.269 & 0.44 & 1.7699 \\
2 & $\mathrm{M}$ & 52 & 0 & 10 & 54 & 2.045 & 0.52 & 1.1570 \\
3 & $\mathrm{M}$ & 21 & 0 & 480 & 56 & 2.904 & 0.57 & 1.0157 \\
4 & $\mathrm{M}$ & 33 & 0 & 30 & 69 & 2.266 & 0.46 & 1.2870 \\
5 & $\mathrm{M}$ & 19 & 0 & 40 & 48 & 2.55 & 0.47 & 1.4527 \\
6 & $\mathrm{M}$ & 41 & 0 & 30 & 32 & 2.056 & 0.4 & 2.4001 \\
7 & $\mathrm{M}$ & 44 & 0 & 60 & 49 & 2.451 & 0.41 & 2.0755 \\
8 & $\mathrm{~F}$ & 34 & 0 & 30 & 48 & 2.643 & 0.46 & 2.0732 \\
9 & $\mathrm{M}$ & 41 & 0 & 240 & 25 & 2.266 & 0.53 & 1.8180 \\
10 & $\mathrm{M}$ & 22 & 0 & 30 & 44 & 2.523 & 0.55 & 1.3377 \\
11 & $\mathrm{M}$ & 28 & 0 & 180 & 49 & 2.915 & 0.5 & 2.0687 \\
12 & $\mathrm{M}$ & 21 & 0 & 10 & 55 & 2.2 & 0.37 & 0.7592 \\
\hline
\end{tabular}

MTBI, mild traumatic brain injury; LOC, loss of consciousness; PTA, post-traumatic amnesia; MRI time-lapse, time between trauma and MRI examination

\section{Time of examination}

Patients were examined between 24-72 $\mathrm{h}$ after the trauma, first by a neurologist, immediatelly followed by MRI and ${ }^{1} \mathrm{H}-\mathrm{MRS}$ examinations. The times were recorded and the brain-imaging delay (MRI time-lapse) was used in the analysis of results.

\section{Statistics}

Due to the non-normal distribution of the continuous data, nonparametric tests (Kruskal-Wallis test and Mann-Whitney U test) were used to analyse the differences between groups. To compare the nominal variables (gender), Fisher's exact test was used. Spearman's rank correlation analysis was performed to compare ${ }^{1} \mathrm{H}-\mathrm{MRS}$ findings with the duration of LOC. Association between 
Table 4. Single-voxel ${ }^{1} \mathrm{H}-\mathrm{MRS}$ findings.

\begin{tabular}{|c|c|c|c|c|}
\hline & Control group & LOC group & NoLOC group & $P$ \\
\hline \multirow[t]{4}{*}{ tNAA/tCre } & $2.5 \pm 0.32$ & $2.14 \pm 0.24$ & $2.42 \pm 0.29$ & $0.003 *(\mathrm{KWT})$ \\
\hline & & & & $0.04 *$ (LOC vs.NoLOC, MWTb) \\
\hline & & & & 0.002* (LOC vs.CON, MWTb) \\
\hline & & & & 1.0 (NoLOC vs.CON, MWTb) \\
\hline \multirow[t]{4}{*}{ tCho/tCre } & $0.50 \pm 0.07$ & $0.44 \pm 0.04$ & $0.47 \pm 0.06$ & $0.047 *(\mathrm{KWT})$ \\
\hline & & & & 0.417 (LOC vs.NoLOC, MWTb) \\
\hline & & & & $0.041 *$ (LOC vs.CON, MWTb) \\
\hline & & & & 1.0 (NoLOC vs.CON, MWTb) \\
\hline Glx/tCre & $1.39 \pm 0.52$ & $1.32 \pm 0.57$ & $1.60 \pm 0.51$ & $0.54(\mathrm{KWT})$ \\
\hline
\end{tabular}

LOC, loss of consciousness; NoLOC, no loss of consciousness; CON, control group; * significant value (P<0.05); KWT, Kruskal-Wallis test; MWTb, Mann Whitney U test with Bonferroni correction

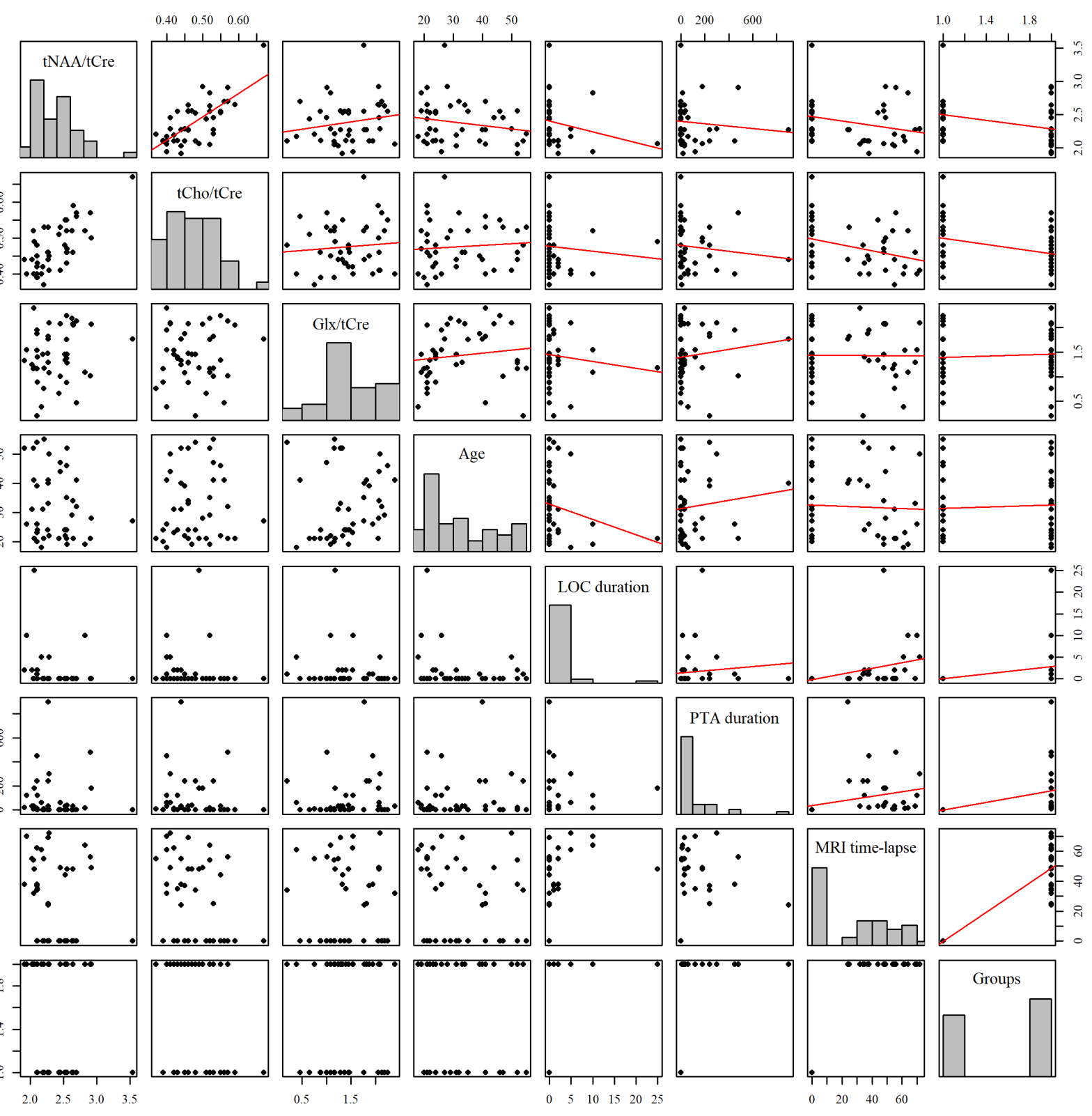

Fig. 2. Scatterplot matrix of the data.

The red line was fitted pairwise by the Ordinary Least Squares method to facilitate exploration of the association between variables. On the diagonal there are estimates of the density of the indicated variable. 
concentration of each metabolite ratios and other parameters (Age, Gender, LOC duration, PTA duration, MRI time-lapse, Control or Patient Group) was visualized by the scatterplot matrix (see Fig. 1) and modeled by the multivariate regression model. The significance level was set to $\alpha=0.05$. The SPSS 15 statistical software package was used for calculations. Regression analysis was performed in R, ver. 4.0.2 ( ref. $^{23}$ ).

\section{RESULTS}

430 patients were screened for the study, but only 24 patients fulfilled our strict entry criteria and agreed to participate in the study. The most common reason for patient exclusion was no witness, therefore no objective information about presence/absence of consciousness. Nineteen healthy volunteers participated in the study. The LOC and NoLOC groups consisted of 12 patients and were similar in gender, age, MRI examination time-lapse after MTBI and duration of PTA (Table 1-3). The mean duration of unconsciousness was $5.5 \pm 6.95 \mathrm{~min}$ and posttraumatic amnesia duration was $148.8 \pm 137.6 \mathrm{~min}$ in the LOC group (Table 1).

tNAA/tCre and tCho/tCre ratios showed significant group differences in the upper brainstem voxel (Table 4.). A lower tNAA/tCre ratio was found in the upper brainstem of patients with LOC when compared to patients without LOC (LOC vs NoLOC; $P=0.04$ ) and to the control group (LOC vs $\mathrm{CON} ; P=0.002$ ). The tNAA/tCre ratio showed no significant difference between $\mathrm{CON}$ and NoLOC $(P=1)$. A significantly lower tCho/tCre ratio was found in patients with LOC when compared to the control group (LOC vs CON; $P=0.041$ ). Other metabolite ratios in the brainstem voxel did not show any significant group differences (Table 4).

Correlations of LOC duration with metabolite ratios were assessed by two methods. Spearman's rank correlation analysis showed significant negative correlation between LOC duration and the tNAA/tCre ratio in the whole (LOC and NoLOC) patient group ( $\mathrm{Ro}=-$ $0.42, P=0.04)$. Other metabolite ratios did not show any correlation with LOC duration ( $P>0.05$, not shown). However, multivariate regression analysis did not show any significant correlation between LOC duration and the metabolite ratios ( $P$-values not shown). The effect size, as measured by the Adjusted R ${ }^{2}$, was $0.1,0,0$ for $\mathrm{tNAA} / \mathrm{tCre}$, tCho/tCre, Glx/tCre, respectively. Association between metabolite ratios and other parameters was visualized by the scatterplot matrix (see Fig. 2).

\section{DISCUSSION}

In the present study, we found subtle metabolic changes in the upper brainstem detected by ${ }^{1} \mathrm{H}-\mathrm{MRS}$ in patients within 3 days after MTBI with post-traumatic unconsciousness. The most significant of the changes was a significant decrease in $\mathrm{tNAA} / \mathrm{tCre}$ ratio in the LOC patient group when compared with the control and NoLOC patient groups. These findings are based on really strict exclusion criteria (including only $5.6 \%$ of screened patients), the groups were age- and gender- matched, and ${ }^{1} \mathrm{H}-\mathrm{MRS}$ voxel was placed in normal-appearing brain tissue, to exclude the possibility of other causes (e.g. preexisting brain trauma, serious internal, neurological, or psychiatric disorders) influencing the results.

Before this study, ${ }^{1} \mathrm{H}-\mathrm{MRS}$ has been used in various other studies in patients after MTBI using various ${ }^{1} \mathrm{H}-\mathrm{MRS}$ methods, investigating various metabolites in various parts of the brain, and with various time-lapse after trauma ${ }^{21,24-29}$. However, ${ }^{1} \mathrm{H}-\mathrm{MRS}$ studies focusing on the relationship between LOC and the brainstem in MTBI are not present in specialist literature, so there are no studies to compare our results with.

There is only a limited number of in-vivo human studies dealing with the relationship between unconsciousness and structural and functional integrity of the brainstem in patients with MTBI. A few diffusion tensor imaging (DTI) studies have reported a relationship between injury to brainstem white matter pathways and the presence or absence of LOC in MTBI patients. In contrast to ours, these studies focused mostly on chronic post-traumatic changes. Jang and Kwon found a narrowing of the dorsal and ventral lower portions of the ARAS in 2 patients, 3 and 11 months after MTBI with LOC, long-term posttraumatic fatigue and hypersomnia ${ }^{17}$. The results of other studies revealed that post-traumatic brainstem changes were not limited to the injury of ARAS. Delano-Wood et al. found that the fractional anisotropy (FA) of the brainstem portion of the corticospinal tract was significantly negatively associated with LOC duration in 58 military veterans, 7.5 years after MTBI (ref. ${ }^{18}$ ). Matthews et al. found a significantly lower FA in 14 brain regions including the bilateral brainstem in patients with MTBI and LOC, when compared to patients without LOC. The time between injury and MRI acquisition was not specified in the study ${ }^{19}$. These DTI findings indicating that subtle posttraumatic changes in the brainstem 1.) are not limited to the injury of ARAS only and 2.) correlate with the presence or absence of LOC, are consistent with our results acquired by ${ }^{1} \mathrm{H}-\mathrm{MRS}$.

Several experimental studies in animal models studied MTBI with LOC and focused on detection of posttraumatic alterations in the brainstem ${ }^{10-12}$. Jane et al. found degenerating axons in the brainstem of animals at 7 days after MTBI with LOC (ref. ${ }^{11}$ ). Brown et al. found ultrastructural and biochemical alterations in the brainstem reticular formation of animals after experimental concussion with transient coma. These changes were characterized with a chromatolysis of neurons, glycogen accumulation in dendrites, terminal parts of axons, and astrocytes. The changes were more visible at 5-7 days after head injury ${ }^{10}$. Browne et al. found extensive brainstem axonal pathology, characterized by swollen axonal bulbs or varicosities that were immunoreactive for accumulating neurofilament protein, in swines 7 days after 
MTBI with prolonged loss of consciousness (10-35 min) (ref. ${ }^{12}$ ). In summary, these experimental studies revealed that MTBI with LOC is associated with subtle developing microscopic and biochemical changes of brainstem and reticular formation, which are evident in the first week after injury. Our findings of significant decrease of tNAA/ tCre ratio, which correlate with neuronal viability ${ }^{30}$, are in correspondence with findings from these experimental animal studies in MTBI with LOC.

We found a significant decrease of $\mathrm{tNAA} / \mathrm{tCre}$ ratio in upper brainstem in MTBI patients with the presence or absence of LOC, but LOC duration was not significantly correlated with any of the metabolite ratios when multivariate regression model was used. There could be two possible explanations: 1.) The selected ${ }^{1} \mathrm{H}-\mathrm{MRS}$ voxel in the upper brainstem was a mixture of grey and white matter. Therefore, we suppose that these metabolic changes resulted from diffuse axonal injury affecting brainstem structures, including, but not limited to, AAn or ARAS. This is supported by animal experimental studies ${ }^{9,11}$ and diffusion tensor imaging (DTI) studies $^{17-19}$. 2.) Our selected ${ }^{1} \mathrm{H}-\mathrm{MRS}$ voxel in the brainstem did not contain the whole AAn. The correlations between LOC parameters (e.g. duration) and severity of AAn/ARAS injury may be found by methods focusing exclusively on AAn/ARAS in its entirety (e.g. DTI) (ref. $\left.{ }^{18}\right)$.

\section{CONCLUSION}

In conclusion, proton magnetic resonance spectroscopy in patients after MTBI is sensitive enough to detect post-traumatic metabolic changes in brain tissue that standard MRI detects as normal. Our findings indicate that ${ }^{1} \mathrm{H}$-MRS may provide a potential biomarker for MTBI associated with LOC.

\section{Ethics Approval and Consent to Participate}

The study was approved by the Ethic committee of Jessenius Faculty of Medicine in Martin, Comenius University in Bratislava, Slovak Republic (No. 1545/2014, Date: 05/NOV/2014) and all participants gave informed consent before participating.

Acknowledgement: The authors are extremely grateful to the patients and healthy volunteers for their collaboration. This work was supported by the VEGA grant No. $1 / 0301 / 19$.

Author contributions: RR, SS, MM, KB, ZK, KEg: literature search; RR, SS, MM,: clinical examination of participants; BM, HP: MRI and ${ }^{1} \mathrm{H}-\mathrm{MRS}$ examination of participants; GM, SS, DR - statistical data analysis; NV, GM, KEm, BJ, TKM, SS, KB, ZK, KEg: general analysis and interpretation of data; RR, SS, MM, DR: manuscript writing; SS, KEg, ZK, KB: supervised the project.

Conflict of interest statement: The authors state that there are no conflicts of interest regarding the publication of this article.

\section{REFERENCES}

1. Carroll LJ, Cassidy JD, Holm L, Kraus J, Coronado VG; WHO Collaborating Centre Task Force on Mild Traumatic Brain Injury. Methodological issues and research recommendations for mild traumatic brain injury: the WHO Collaborating Centre Task Force on Mild Traumatic Brain Injury. J Rehabil Med 2004;(43 Suppl):113-25.

2. McCrory P, Meeuwisse WH, Aubry M, Cantu RC, Dvořák J, Echemendia RJ, Engebretsen L, Johnston K, Kutcher JS, Raftery M, Sills A, Benson BW, Davis GA, Ellenbogen R, Guskiewicz KM, Herring SA, Iverson GL, Jordan BD, Kissick J, McCrea M, McIntosh AS, Maddocks D, Makdissi M, Purcell L, Putukian M, Schneider K, Tator CH, Turner M. Consensus statement on concussion in sport: the 4th International Conference on Concussion in Sport, Zurich, November 2012. J Athl Train 2013;48(4):554-75.

3. Edlow BL, Giacino JT, Wu O. Functional MRI and outcome in traumatic coma. Curr Neurol Neurosci Rep 2013;13(9):375.

4. Snider SB, Bodien YG, Bianciardi M, Brown EN, Wu O, Edlow BL. Disruption of the ascending arousal network in acute traumatic disorders of consciousness. Neurology 2019;93(13):e1281-e87.

5. Moruzzi G, Magoun HW. Brain stem reticular formation and activation of the EEG. Electroencephalogr Clin Neurophysiol 1949;1(4):45573.

6. Plum F, Posner JB. States of acutely altered consciousness. In: Plum F, Posner JB, editors. The Diagnosis of Stupor and Coma. 3rd ed. Philadelphia, PA: FA Davis; 1982. p. 3-5.

7. Mitchell DE, Adams JH. Primary focal impact damage to the brainstem in blunt head injuries. Does it exist? Lancet 1973;2(7823):21518.

8. Smith DH, Nonaka M, Miller R, Leoni M, Chen XH, Alsop D, Meaney DF. Immediate coma following inertial brain injury dependent on axonal damage in the brainstem. J Neurosurg 2000;93(2):315-22.

9. Ommaya AK, Gennarelli TA. Cerebral concussion and traumatic unconsciousness. Correlation of experimental and clinical observations of blunt head injuries. Brain 1974;97(4):633-54.

10. Brown WJ, Yoshida N, Canty T, Verity MA. Experimental concussion. Ultrastructural and biochemical correlates. Am J Pathol 1972;67:4168.

11. Jane JA, Steward O, Gennarelli T. Axonal degeneration induced by experimental noninvasive minor head injury. J Neurosurg 1985;62:96-100.

12. Browne KD, Chen XH, Meaney DF, Smith DH. Mild traumatic brain injury and diffuse axonal injury in swine. J Neurotrauma 2011;28(9):1747-55.

13. Einarsen CE, Moen KG, Håberg AK, Eikenes L, Kvistad KA, Xu J, Moe HK, Tollefsen MH, Vik A, Skandsen T. Patients with Mild Traumatic Brain Injury Recruited from Both Hospital and Primary Care Settings: A Controlled Longitudinal Magnetic Resonance Imaging Study. J Neurotrauma 2019;36(22):3172-182.

14. Firsching $R$, Woischneck D, Diedrich $M$, Klein S, Ruckert A, Wittig $H$, Dohring $W$. Early magnetic resonance imaging of brainstem lesions after severe head injury. J Neurosurg 1998;89:707-12.

15. Weiss N, Galanaud D, Carpentier A, Tezenas de Montcel S, Naccache L, Coriat P, Puybasset L. A combined clinical and MRI approach for outcome assessment of traumatic head injured comatose patients. J Neurol 2008;255(2):217-23.

16. Carpentier A, Galanaud D, Puybasset L, Muller JC, Lescot T, Boch AL, Riedl V, Cornu P, Coriat P, Dormont D, van Effenterre R. Early morphologic and spectroscopic magnetic resonance in severe traumatic brain injuries can detect "invisible brain stem damage" and predict "vegetative states". J Neurotrauma 2006;23(5):674-85.

17. Jang $\mathrm{SH}, \mathrm{Kwon} \mathrm{HG}$. Injury of the Ascending Reticular Activating System in Patients With Fatigue and Hypersomnia Following Mild Traumatic Brain Injury: Two Case Reports. Medicine (Baltimore) 2016;95(6):e2628.

18. Delano-Wood L, Bangen KJ, Sorg SF, Clark AL, Schiehser DM, Luc $\mathrm{N}$, Bondi MW, Werhane M, Kim RT, Bigler ED. Brainstem white matter integrity is related to loss of consciousness and postconcussive symptomatology in veterans with chronic mild to moderate traumatic brain injury. Brain Imaging Behav 2015;9(3):500-12.

19. Matthews SC, Spadoni AD, Lohr JB, Strigo IA, Simmons AN. Diffusion tensor imaging evidence of white matter disruption associated with loss versus alteration of consciousness in warfighters exposed to 
combat in Operations Enduring and Iraqi Freedom. Psychiatry Res 2012;204(2-3):149-54.

20. Gonzalez PG, Walker MT. Imaging modalities in mild traumatic brain injury and sports concussion. PM\&R 2011;3(10 Suppl 2): S413-24.

21. Sivák Š, Bittšanský M, Grossmann J, Nosál' V, Kantorová E, Siváková J, Demková A, Hnilicová P, Dobrota D, Kurča E. Clinical correlations of proton magnetic resonance spectroscopy findings in acute phase after mild traumatic brain injury. Brain Inj 2014;28(3):341-6.

22. Provencher SW. Automatic quantitation of localized in vivo $1 \mathrm{H} \mathrm{spec}$ tra with LCModel. NMR Biomed 2001;14(4):260-4.

23. R Core Team. R: A language and environment for statistical computing. R Foundation for Statistical Computing 2020, Vienna, Austria. URL https://www.R-project.org/.

24. Cohen BA, Inglese M, Rusinek H, Babb JS, Grossman RI, Gonen O. Proton MR spectroscopy and MRI-volumetry in mild traumatic brain injury. AJNR Am J Neuroradiol 2007;28(5):907-13.

25. Cartwright PE, Perkins TG, Wilson SH, Weaver LK, Orrison WW. Analysis of magnetic resonance spectroscopy relative metabolite ratios in mild traumatic brain injury and normative controls. Undersea Hyperb Med 2019;46(3):291-97.
26. Kirov I, Fleysher L, Babb JS, Silver JM, Grossman RI, Gonen O. Characterizing 'mild' in traumatic brain injury with proton MR spectroscopy in the thalamus: Initial findings. Brain Inj 2007;21(11):114754.

27. Signoretti S, Vagnozzi R, Tavazzi B, Lazzarino G. Biochemical and neurochemical sequelae following mild traumatic brain injury: summary of experimental data and clinical implications. Neurosurg Focus 2010;29(5):E1.

28. Govind V, Gold S, Kaliannan K, Saigal G, Falcone S, Arheart KL, Harris $\mathrm{L}$, Jagid J, Maudsley AA. Whole-brain proton MR spectroscopic imaging of mild-to-moderate traumatic brain injury and correlation with neuropsychological deficits. J Neurotrauma 2010;27(3):483-96.

29. Veeramuthu V, Seow P, Narayanan V, Wong JHD, Tan LK, Hernowo AT, Ramli N. Neurometabolites Alteration in the Acute Phase of Mild Traumatic Brain Injury (mTBI): An In Vivo Proton Magnetic Resonance Spectroscopy (1H-MRS) Study. Acad Radiol 2018;25(9):1167-77.

30 Stovell MG, Yan JL, Sleigh A, Mada MO, Carpenter TA, Hutchinson PJA Carpenter KLH. Assessing Metabolism and Injury in Acute Human Traumatic Brain Injury with Magnetic Resonance Spectroscopy: Current and Future Applications. Front Neurol 2017;8:426. 